\title{
Role of Emotional Intelligence on Job Satisfaction in University Teacher \\ Saira Siddique
}

Institute of Rural Home Economics, University of Agriculture, Faisalabad, Pakistan

Farah Riaz

Institute of Rural Home Economics, University of Agriculture, Faisalabad, Pakistan

Aisha Siddique

Institute of Rural Home Economics, University of Agriculture, Faisalabad, Pakistan

Ayesha Riaz

Institute of Rural Home Economics, University of Agriculture, Faisalabad, Pakistan

Yasir Nawaz

Department of Sociology, University of Sargodha, Sargodha, Pakistan

Sameen Shehzadi

Department of Sociology, University of Sargodha, Sargodha, Pakistan

\section{Doi:10.5901/ajis.2014.v3n6p327}

\section{Abstract}

\begin{abstract}
Emotional intelligence and job satisfaction are two concepts of high importance in the modern work environment. They serve as a competitive verge in personal and organizational life. The teaching profession is one the most important profession. A teacher can mold the future every day in the class. A teacher can make the world a better place, giving young people the best start in life and can use his own education to the fullest and best extent. The knowledge of Emotional Intelligence could help teachers to harvest great advantages from their profession. Teachers in today's education system face excessive expectations and demands such as increased accountability, negative student attitudes, low status of the profession and low paying salaries. As a result of these demands many teachers experience job dissatisfaction. The present research identified the role of Emotional Intelligence on Job Satisfaction and also assesses the level of job satisfaction in male and female teachers. Teachers were asked to fill, the Self Report Measure of Emotional Intelligence, and the Job Descriptive Index. It was hypothesized that there is a significant relationship between Emotional Intelligence and Job Satisfaction. The teacher of higher education institutes were the respondents. The collected data was analyzed by chi square and gamma test. Results demonstrate a significant association between Emotional Intelligence and Job Satisfaction. Age differences were also found as young teachers are highly Emotionally Intelligent and Satisfied with their job than older teachers.
\end{abstract}

Keywords: Emotional Intelligence, University, Job Satisfaction, job descriptive index

\section{Introduction}

The role and responsibilities of university faculty members are closely attach to the essential functions of higher education. The function of college and universities are "to advance inquisition and to advance the computation of human acquaintance, to offer the common instructions to the students, and to develop experts for various fields of public service. Likewise university faculty members and teachers commence research, teaching roles to carry out the academic work of their respective institutions.

So teachers' job satisfaction is important that it may have a direct impact on students learning ability as well as teaching efficiency. Teaching is a noble and important profession as described by Iwanicki (2001).The quality may 
receive ' by the students may be influenced by the level of job satisfaction (Jones, 2002). In addition to having attitudes about their jobs as a whole. People also can have attitudes about various aspects of their jobs such as the kind of work they do, their coworkers, supervisors or subordinates and their pay (George et al., 2008).

Emotional intelligence plays an important role in this matter by it has its roots in the social intelligence. El is the ability to distinguish, appraise and express emotions to act access and produce feelings when facilitated thoughts to understand emotions and emotional knowledge and to regulate emotions to promote emotional intellectual growth. (Mayer and Salovey 1990) A person has to work in a collaborative environment and it is necessary to control and understand the emotions of self and others. Emmerling and Cherniss (2003) noted that emotions are connected with mental processes so that it has an impact on profession decision-making. They also suggested that emotions may produce superior decisions, not inferior.

Actually El is the parameter which can be used in effort to know and identify the workers performance within the work setting (Sy et al., 2006).

Goleman'sEl theory of performance had direct applicability to the domain of work and in predicting excellence in all jobs from sales to leadership (Goleman, 1998). Goleman believed that increased understanding of emotional intelligence allowed individuals to flourish in their lives, as citizens in their communities, and on their jobs. To support this statement, the latter in particular, Goleman proposed a theory of performance that was built on the basic emotional intelligence model by Mayer and Salovey (1993) and adapted this original model to predict peoples' personal effectiveness at work and in leadership. To do this, Goleman made the case for the importance of emotional intelligence in the workplace and set forth guidelines for effective individual development. The framework of El that translated into on the job success, as postulated by Goleman, were the skills of self-awareness, selfmanagement, social awareness, and relationship management. This model was based on El competences that were identified in internal research at corporations and organizations as unique outstanding performers (Goleman, 1998).

\section{Materials and Methods}

The present study was conducted in Faisalabad city. Two government Universities were selected. Carefully chosen samples (who were associate professors and lecturers) used to represent the population. The sample reflects the characteristics of the population from which it is drawn.A total sample of 86 females and 114males were chosen. In order to investigate the differences based on socioeconomic status gender and monthly income a demographic sheet was prepared. Job Descriptive Index and Self Report Measure for Emotional Intelligence were used to collect the data.After collecting the data was analyzed through SPSS (Statistical Package for Social Sciences) and meaningful, presentable Statistical technique such as frequency distribution and percentage analysis and chi-square.

\section{Results and Discussions}

The present study indicates that there are total 200 respondents in which $57 \%$ percent of the respondents were the male and $43 \%$ percent respondents were females (Table 1 ).

Table 1: Distribution of respondents according to gender

\begin{tabular}{|c|c|c|}
\multicolumn{3}{|c|}{$\mathbf{N}=\mathbf{2 0 0}$} \\
\hline Gender & Frequency & Percentage \\
\hline Male & 114 & 57.0 \\
\hline Female & 86 & 43.0 \\
\hline Total & 200 & 100.0 \\
\hline
\end{tabular}

According to demographic sheet $33.5 \%$ of the respondents were up to the age of 30 and $48 \%$ were 31 to 40 years of age and $18 \%$ were above the age of 40 years (Table 2). 
Table 2: Distribution of respondents according to age

\section{$\mathrm{N}=200$}

\begin{tabular}{|c|c|c|}
\hline Age (in years) & Frequency & Percentage \\
\hline Up to 30 & 67 & 33.5 \\
\hline $31-40$ & 97 & 48.5 \\
\hline Above 40 & 36 & 18.0 \\
\hline Total & 200 & 100.0 \\
\hline
\end{tabular}

Family type also impacted on the overall job satisfaction because a person has to support his entire family expenses. $59 \%$ of the respondents were living in nuclear families and $41 \%$ of the respondents were from joint families (Table 3 ).

Table 3: Distribution of respondents according to family type

\begin{tabular}{|c|c|c|}
\multicolumn{3}{|c|}{$\mathbf{N}=\mathbf{2 0 0}$} \\
\hline Family type & Frequency & Percentage \\
\hline Nuclear & 118 & 59.0 \\
\hline Joint & 82 & 41.0 \\
\hline Total & 200 & 100.0 \\
\hline
\end{tabular}

$95 \%$ of the respondents respond that they enjoy their teaching job and only 5\%are those who didn't enjoy their teaching job (Table 4).

Table 4: Distribution of respondents according to extent of enjoyment of teaching job

\begin{tabular}{|c|c|c|}
\multicolumn{4}{|c|}{$\mathbf{N}=\mathbf{2 0 0}$} \\
\hline Enjoy teaching & Frequency & Percentage \\
\hline Very much & 190 & 95.0 \\
\hline Not much at all & 10 & 5.0 \\
\hline Total & 200 & 100.0 \\
\hline
\end{tabular}

From the survey it is observed that $94 \%$ respondents enjoy their present job and only $6 \%$ doesn't enjoy their present job (Table 5).

Table 5: Extent of enjoyment of present job

\begin{tabular}{|c|c|c|}
\multicolumn{2}{|c|}{$\mathbf{N}=\mathbf{2 0 0}$} \\
\hline Extent of enjoyment & Frequency & Percentage \\
\hline Very much & 188 & 94.0 \\
\hline Don't enjoy & 12 & 6.0 \\
\hline Total & 200 & 100.0 \\
\hline
\end{tabular}

Data also depict that there is a significant relationship between emotional intelligence and job satisfaction (Table 6).Goleman believed that increased understanding of emotional intelligence allowed individuals to flourish in their lives, as citizens in their communities, and on their jobs. Nahid Naderi (2012) elaborates that there is a positive association between Emotional Intelligence and Job Satisfaction. 


\subsection{Hypothesis 1: There is a significant relationship between emotional intelligence and job satisfaction}

Table 6: Association between job satisfaction and emotional intelligent

\begin{tabular}{|c|c|c|c|c|}
\hline \multirow{2}{*}{ Job satisfaction } & \multicolumn{3}{|c|}{ Emotional intelligent } & \multirow{2}{*}{ Total } \\
\cline { 2 - 5 } & Low & Medium & High & \\
\hline \multirow{2}{*}{ Low } & 11 & 17 & 8 & 36 \\
\cline { 2 - 5 } & $30.6 \%$ & $47.2 \%$ & $22.2 \%$ & $100.0 \%$ \\
\hline \multirow{2}{*}{ Medium } & 43 & 49 & 16 & 108 \\
\cline { 2 - 5 } & $39.8 \%$ & $45.4 \%$ & $14.8 \%$ & $100.0 \%$ \\
\hline \multirow{2}{*}{ High } & 2 & 39 & 15 & 56 \\
\cline { 2 - 5 } & $3.6 \%$ & $69.6 \%$ & $26.8 \%$ & $100.0 \%$ \\
\hline \multirow{2}{*}{ Total } & 56 & 105 & 39 & 200 \\
\cline { 2 - 5 } & $28.0 \%$ & $52.5 \%$ & $19.5 \%$ & $100.0 \%$ \\
\hline
\end{tabular}

Chi-square $=24.65$ d.f. $=4$ Significance $=0.000^{\star *}$ Gamma $=.309$ ** $=$ Significant

From the present study it is also concluded that young staff members were highly emotional intelligent than older faculty members (Table 7). This result is unexpectedly contradicts with the previous literature as most of the researches demonstrate that as people age their El gets higher. A research conducted under the supervision of psychologist Dr. Robert Levenson (2011) revealed that cognitive skills and El can actually sharpen as people enter in their 60s, giving older people benefit in the personal relationships and in work place. A study conducted by San Mateo (2013), conducted a study on examining the relationship between age and El. The study examined three aspects of El and results shows that self-awareness, self-management and self-direction. Self-awareness increases slightly with age. Self-management does not increase with age. Thirdly the relationship between age and "Give Yourself" is modest - age is no guarantee for vision and wisdom.

\subsection{Hypothesis 3: Young teachers are more emotionally intelligent then old teacher}

Table 7: Association between age of the respondents and their emotional intelligence

\begin{tabular}{|c|c|c|c|c|}
\hline \multirow{2}{*}{ Age of the respondents (in years) } & \multicolumn{3}{|c|}{ Emotional intelligence } & \multirow{2}{*}{ Total } \\
\cline { 2 - 5 } & Low & Medium & High & \\
\hline \multirow{2}{*}{ Up to 30 } & 7 & 45 & 15 & 67 \\
\cline { 2 - 5 } & $10.4 \%$ & $67.2 \%$ & $22.4 \%$ & $100.0 \%$ \\
\hline \multirow{2}{*}{$31-40$} & 39 & 44 & 14 & 97 \\
\cline { 2 - 5 } & $40.2 \%$ & $45.4 \%$ & $14.4 \%$ & $100.0 \%$ \\
\hline \multirow{2}{*}{ Above 40 } & 10 & 16 & 10 & 36 \\
\cline { 2 - 5 } & $27.8 \%$ & $44.4 \%$ & $27.8 \%$ & $100.0 \%$ \\
\hline \multirow{2}{*}{ Total } & 56 & 105 & 39 & 200 \\
\cline { 2 - 5 } & $28.0 \%$ & $52.5 \%$ & $19.5 \%$ & $100.0 \%$ \\
\hline
\end{tabular}

Chi-square $=19.49$ d.f. $=4$ P-value $=.001$ Gamma $=-.196$

It is also observed from the study that young teachers were more satisfied with their job than older teachers (Table 8). This result also contradicts with the previous researches and literature. Bernalet al., (2005), explored the interaction between job satisfaction and age. They showed a significant interaction between age and job satisfaction but this relationship is weak and positive. That explains that age failed to show a considerable proportionality for linear variance in job satisfaction measure. Their resultalso showed that ageis not a feasible predictor of job satisfaction. The reason why young teachers are more satisfied with their jobs than older ones. The first and most important reason is that they suppose time limit is very accurate. Teaching job is not an over burden job. Young teachers who get jobs right after their studies consider their pay more than enough they need. 


\subsection{Hypothesis 5: Young teachers are more satisfied with their job then old teacher}

Table 8: Association between age of the respondents and their satisfaction with job

\begin{tabular}{|c|c|c|c|c|}
\hline \multirow{2}{*}{ Age of the respondents (in years) } & \multicolumn{3}{|c|}{ Job satisfaction } & \multirow{2}{*}{ Total } \\
\cline { 2 - 5 } & Low & Medium & High & \\
\hline \multirow{2}{*}{ Up to 30 } & 4 & 41 & 22 & 67 \\
\cline { 2 - 5 } & $6.0 \%$ & $61.2 \%$ & $32.8 \%$ & $100.0 \%$ \\
\hline \multirow{2}{*}{$31-40$} & 28 & 43 & 26 & 97 \\
\cline { 2 - 5 } & $28.9 \%$ & $44.3 \%$ & $26.8 \%$ & $100.0 \%$ \\
\hline \multirow{2}{*}{ Above 40 } & 4 & 24 & 8 & 36 \\
\cline { 2 - 5 } & $11.1 \%$ & $66.7 \%$ & $22.2 \%$ & $100.0 \%$ \\
\hline \multirow{2}{*}{ Total } & 36 & 108 & 56 & 200 \\
\cline { 2 - 5 } & $18.0 \%$ & $54.0 \%$ & $28.0 \%$ & $100.0 \%$ \\
\hline
\end{tabular}

Chi-square $=17.12$ d.f. $=4$ P-value $=.002^{\star \star}$ Gamma $=-.182^{* \star}=$ Highly significant

\section{Conclusion}

In the present study $57 \%$ of the respondents were males and $43 \%$ of the respondents were female. $33.5 \%$ of the respondents were up to 30 years old, $48.5 \%$ of the respondents were among $31-40$ years and only $18 \%$ of the respondents were 40 years old. Family type is also consider a predictor of job satisfaction. $59 \%$ of respondents were living in nuclear families and $41 \%$ were living in joint families. A majority of $26.8 \%$ of the respondents were highly emotional intelligent and satisfied with their jobs. Nahidnaderi (2012) elaborates that there is a positive association between Emotional Intelligence and Job Satisfaction. From the result it is also concluded that young teachers $22.2 \%$ were highly emotional intelligent than older teachers. The reason behind this is that older adults are stubborn and inflexible in their thoughts and actions and can't change their thinking pattern. It is also observed from the study that a majority $32.8 \%$ of young teachers were satisfied with their teaching job than older faculty members. Bernalet al., (2005), explored the interaction between job satisfaction and age. They showed a significant interaction between age and job satisfaction but this relationship is weak and positive. That explains that age failed to show a considerable proportionality for linear variance in job satisfaction measure. Their resultalso showed that ageis not a feasible predictor of job satisfaction.

\section{Recommendations}

In the light of the results of this research there are some suggestions for the teachers and university authorities to improve the employee's performance and competence:

1. El awareness programs should be launched in the university in order to enhance the El among university teachers.

2. Supervisory support and assessment is necessary for the faculty members to perform well.

3. Supervisory support also helps to improve the relationship among colleagues and foster them to cooperate.

4. Regular promotions encourage the teachers to perform their best for the better results of students.

5. According to the results teacher should try to improve their El to perform well in the social settings and on job as well.

\section{References}

Bernal et al.,(2005). Job satisfaction: empirical evidence of gender difference, Women In Management Review, 20 (4):279 - 288

Dr. Robert Levenson. (2011).Emotional Intelligence Gets Better With Age. California

Emmerling, R. \&Cherniss. 2003. Emotional intelligence and the career choice process.

George, J.M. and Jones, G.R. 2008. Understanding and Managing Organizational behavior, Fifth Edition,Pearson/Prentice Hall, New Yersey, p. 78

Goleman, D. 1998. Working with emotional intelligence. New York: Bantam Books.

Iwanicki, E. 2001.Understanding and alleviating teacher burnout. Theory Into Practice, 22.

Jones, W. 2002, February. Making a difference through teaching. Black Collegian, 32, 2-4.

Mayer, J., and P.Salovey. 1993. The intelligence of emotional intelligence. Intelligence, 17: 433- 442.

Mayer, J., and P.Salovey. 1997. What is emotional intelligence? Emotional development andemotional intelligence: Implications for 
educators. New York: Basic Books.

Nahid .N, 2012. Teachers: emotional intelligence, job satisfaction and organizational commitment, journal of workplace, 24: 256-269.

Sy, T., S. Tram., and and L. A. O'Hara. 2006. Relation of employee and manger emotional intelligence to job satisfaction and performance.In Journal of Vocational Behavior, 68: 461-473. 